\title{
Bilingual practices as a means of intercultural communication under the globalization
}

\author{
Olga Tomyuk ${ }^{1}$, Margarita Dyachkova ${ }^{2}$, Anna Shutaleva $^{1}{ }^{*}$, Anastasia Novgorodtseva $^{1}$, Andrei Dudchik ${ }^{3}$ \\ ${ }^{1}$ Ural Federal University named after the first President of Russia B.N. Yeltsin, 620075. Ekaterinburg, Russian Federation \\ ${ }^{2}$ Ural State Pedagogical University, 620017 Ekaterinburg, Russian Federation \\ ${ }^{3}$ Institute of Philosophy of the National Academy of Sciences of Belarus, Belarusian State University, Minsk, Belarus
}

\begin{abstract}
The article is devoted to the problem of intercultural communication and identifying the significance of bilingual practices in the context of globalization. A review of the research on this issue proposes to consider bilingual practices as a means of intercultural communication. A review of the research on this issue proposes to consider bilingual practices as a means of intercultural communication. It is proved that the basis of bilingual practices of students of the university is social action. The results of a theoretical analysis of the problem and practical activities in this area confirm the possibility of designing bilingual practices as an effective means of intercultural communication. The novelty of the research consists in substantiating the potential of bilingual practices for solving intercultural communications that are significant for students of the university. The bases of this study performed on the methodological foundations of the activity and socio-cultural approaches. The results of the inclusion of bilingual practices as educational and extracurricular events in the communicative activities of students through training on the educational programs of the university, organization of project activities aimed at developing their intercultural competence are formulated
\end{abstract}

\section{Introduction}

Globalization as an objective process of the current stage of human development is associated with increasing interconnection and interdependence between countries, cultures, nations, covers all spheres of human activity, is a response to the challenges of the information revolution, always and significantly affects people's lives.

In the era of globalization, intercultural communications intensify, as a result of which the world becomes a single communicative space. The concept of "intercultural communication" was introduced by E. Hall as a result of his study of the communicative function of culture, the relationship of culture and communication. He defined intercultural communication as a unique area of human relations [1]. On the one hand, globalization contributes to overcoming political and ideological barriers, conflicts, aggression, and on the other, it generates the risks associated with the unification, destruction of cultural identity and the traditional values of primary cultures. This circumstance actualizes the appeal to modern practices of interaction between people, such as the bilingual practices of modern intercultural communication.

\section{Materials and methods}

The article aims to study intercultural communication in the context of globalization and to identify the significance of bilingual practices in this process.

The use of bilingual practices in the learning process aims at updating sign, denotative, or situational connections of lexical units in the student's work process in two language systems. The peculiarity of bilingual education is the comprehension of the world of knowledge by students is carried out in a dialogue of different cultures, with the second language being the language of instruction and the means of communication. Based on bilingual practices, it is possible to create intercultural communication in contact with another culture. Bilingual practices in learning contribute to the realization of the dialogue of cultures and individuals as carriers of culture, while the individual enters into dialogue on behalf of the social "we," that sociocultural community where his personal development took place. Dialogism based on the bilingualism of the subjects of interaction is the essential characteristic of intercultural communication.

\section{Results}

Let us consider bilingual practices as an example of the Ural Federal University named after the first President of

\footnotetext{
* Corresponding author: ashutaleva@yandex.ru
} 
Russia B.N. Yeltsin. So, entering the university, all students, regardless of the direction of preparation, study a foreign language; basically, the choice is between three languages: English, German, French.

The Ural Federal University is positioning itself as an educational space, a research space open to communication with representatives of different cultures, countries, and peoples. Bilingual practices at the Ural Federal University are implemented through meetings with world-famous scientists, participation in scientific conferences (manifestations of bilingualism: for example, the speaker's presentation in English, the report in Russian). Bilingual practices expand the possibilities of intercultural communication between students and teachers.

The Ural Federal University has more than one hundred partner universities, is included in the program of academic mobility, in the programs "Erasmus +," "North 2 North" - an exchange with universities in Iceland, Finland, Sweden, Norway, Canada and the USA (Alaska), "Mevlana." Ural Federal University exchanges students with universities in Turkey. The programs of academic mobility motivate students to engage in the practice of bilingualism in order to subsequently build their educational, research, professional trajectory not only in Russia but also in partner countries.

Educational programs with in-depth mastery of languages are actively designed and implemented at the Ural Federal University: two foreign languages are studied from the first year: the first foreign language is English, the second is at the student's choice (Chinese, Japanese, Korean, Arabic, Turkish, Spanish, Italian, French, Deutsch).

Ural Federal University has bilingual education programs that serve as a tool for updating the content of intercultural communications. So, the Department of Philosophy in the framework of the training direction 04/27/01 "Philosophy" in English is implementing the educational program "Political Philosophy" (master's level) for students from around the world. As a result of mastering the program, graduates demonstrate a willingness to communicate in both their native and English languages.

The direction of preparation - 04/45/01 "Philology," the educational program "Teaching Russian as a Foreign Language" (master's level) is aimed at developing students' readiness for communication to solve the problems of professional activity in Russian and foreign languages, possession of communicative strategies and tactics in various areas of communication.

In the framework of the training direction - 04/41/01 "Foreign regional studies", the program "Comprehensive regional studies" (master's level) is being implemented, aimed at developing intercultural competence among students - readiness to work in a multicultural team and a tolerant attitude to intercultural differences, the ability to communicate in a professional environment in a foreign language.

The above-mentioned educational programs are of great interest to foreign citizens who want to get higher education at Russian universities. Due to the presence of representatives from different cultures, communication is carried out in both Russian, English, and other foreign languages. It should be noted that intercultural communication is not limited to the interaction of individuals belonging to different cultures and speaking different languages. The conditions for effective intercultural communication are, in addition to knowledge of foreign languages, an understanding of the behavior patterns of communicative partners, knowledge of their culture, value system, and world views. Intercultural communication should be considered as a process of interaction between cultures, language and the subject as a carrier of culture, aimed at mutual understanding and understanding, as a result - the transfer and development of sociocultural experience, enrichment of personal experience, rapprochement of people of different cultures. Educational programs as bilingual practices contribute to the continuous development of intercultural communication, mutual understanding of communicants at the interpersonal and intergroup levels, and the expansion of the field of subjects with value status.

The Ural Federal University is open for admission of citizens from different subjects of the Russian Federation, near and far abroad, which is a condition for the development of significant bilingual practices, for example, teaching students in mixed groups at educational programs in different areas of training, where Russian students study together with citizens of foreign countries. Students from neighbouring countries are citizens of the Republic of Kazakhstan, the Republic of Tajikistan, the Republic of Azerbaijan, and the Kyrgyz Republic; international students - citizens of the People's Republic of China, the Republic of Turkey, the Socialist Republic of Vietnam, the Republic of Senegal, the Hashemite Kingdom of Jordan, the Syrian Arab Republic, the Republic of Colombia, the Federative Republic of Brazil, the Mexican United States, the Kingdom of the Netherlands, the Kingdom of Denmark, the Bolivarian Republic of Venezuela, the Federative Republic of Germany. Such a vast geography of international students is evidence that Ural Federal University is a university with an international brand, which created the conditions for intercultural communication of representatives of different cultures.

In addition to the intercultural bilingual educational space, the Ural Federal University also has a system of supporting bilingualism in extracurricular activities: the LinguaT, Choral, Foreign Languages Club projects, and others. For example, the choral ensemble forms the experience and practice of bilingualism by choosing a repertoire for joint projects of students of different cultures (concerts, competitions, advertising, interacting with the media, touring activities, festivals), establishing business and friendly contacts with foreign musicians.

Linguistic Theater "LinguaT" is a unique linguistic theater with the possibility of developing intercultural competence: staging performances in foreign languages (English, French, German, Spanish, Italian, Chinese), learning languages with teachers in the process of working on theatre productions, participating in trips to festivals Russian and international levels, sign with the works of international authors in the original. 
Separately, we highlight the bilingual project "Board of European Students of Technology (BEST) Ekaterinburg Ural Federal University," aimed at expanding intercultural communications of the Ural Federal University. The goal of the project as an effective bilingual practice is to improve the level of English language proficiency by including international students in events of various levels (international, regional, all-Russian), for example, a visiting school, international engineering competitions - EBEC. At present, the space of intercultural communication is becoming borderless.

The expansion of bilingualism practices for students of the Ural Federal University is also associated with the fact that many international events and projects are being implemented in Russia. Over the years, the INNOPROM project has been implemented in Ekaterinburg as a platform for intercultural professional communication, with 107 countries participating in it, more than a thousand journalists from around the world cover events. Ekaterinburg was one of the organizers of the World Cup (2018), hundreds and thousands of people from around the world became guests and fans of it. Russian and international students of the Ural Federal University had the opportunity of intercultural communication through participation in bilingual volunteer practice.

\section{Discussion}

\subsection{Intercultural communication in the context of globalization: concepts of understanding and implementation features}

Intercultural communication can be characterized in terms of its different processes:

- "globalization - localization," associated, on the one hand, with the tendency of acquiring the status of "citizen of the world," and, on the other, the desire not to lose their own cultural identity;

- "universalization - individualization," that is, integration, the formation of a single space, and, at the same time, the growth of cultural identity.

Consider some approaches to understanding intercultural communication in the context of globalization.

Let us dwell on the concept of intercultural communication of sociologist J. Ritzer (USA), which received the common name "McDonaldization concept" [2]. McDonaldization is a modern model of formal rationality, characterized by the introduction of the principles of fast restaurant service (McDonald's, PIZZA MIA, Burger King, KFC) into various spheres of life education, banking, health care, media. The model is based on the principles: economic efficiency, predictability of consequences of actions, reliability, technologically prescribed control without taking into account the personal factor, computability of costs and time These necessary provisions of McDonaldisation ensured the global attractiveness of the model, its implementation [2].
According to the concept of hybridization by $\mathrm{J}$. Peters, integration, the interpenetration of elements of one culture into another, the inculcation of these elements in another culture is interpreted as cultural hybridization [3]. The essence of cultural hybridization is that, despite the intensity of the processes of intercultural interaction, the consequence will not necessarily be the unification and standardization of cultures, since at the junction of culture they can combine national, regional with global world trends flexibly. There is also a mechanical transfer of Western samples of culture without taking into account regional, national specifics, which, as a result, leads to the loss of identity.

R. Robertson (USA) interprets globalization as a series of changes aimed at turning the world into a "single place": the world shrinks a single social space that does not have barriers. People, being at different ends of the planet, may be involved in the same events, which are elements of the same process of intercultural interaction. R. Robertson, one of the authors of the concept of globalization, distinguishes two directions in globalization:

- global institutionalization of the lifeworld, that is, the organization of daily local interactions by the direct influence of large-scale macrostructures (world mass media, behavior patterns in the media);

- Localization of globality (interaction of cultures with the inclusion in the daily life of elements of local, "exotic" cultures). Localization is a defensive reaction in connection with the fear of losing identity before the threat of absorption by unification processes.

R. Robertson believes that both in the past and current conditions, globalization occurs along with "globalization," that is, the adaptation of cultural elements to different local conditions based on local traditions. Therefore, it is not standardization that occurs, but the assertion of heterogeneity of vital activity as a normative standard. Thus, in the process of forming a new world culture, the principles of cultural homogeneity and heterogeneity are combined. This makes it possible not only to preserve but also revive traditions [4].

R. Robertson introduces the term "globalization" to denote the two-tier nature of globalization. R. Robertson believes that globalization manifested in the resistance of local cultures to globalization processes (universalization, standardization, unification) and the desire of local structures to preserve their identity. Otherwise, intercultural communication characterizes the culture in terms of its ability to perceive other cultural elements and translate its values into other cultures. According to the concept of R. Robertson, the interaction of global and local is one of the essential characteristics of the state of the modern world, when not only the sociocultural tendencies dominating the world influence national cultures but also the originality of national cultures is reflected in global culture.

Thus, in the concepts of McDonaldization, globalization, and hybridization, the emphasis is placed on various aspects of intercultural communication, they present different opinions of scientists on the 
communicative processes taking place in the modern world. Despite this, all the processes of intercultural communication (unification, identification, differentiation, localization, hybridization) somehow coexist in the sociocultural space of all states.

The problems of intercultural communication cause the need to study foreign languages and search for new approaches to teaching foreign languages [5]. The position began to be actively affirmed: for the effective establishment of intercultural contacts, both linguistic and cultural skills are necessary; teaching a foreign language should be aimed at real intercultural communication, mutual understanding, equal interaction between people, speakers of different languages, representatives of different communities and cultures. In this regard, in domestic studies, there has been a tendency to identify factors, means of intercultural communication and intercultural interaction, ways of exchanging information, emotions between people from different cultures, updating their characteristics.

It should be noted one more feature of intercultural communication related to the fact that participants in a communicative act in direct contact use different language strategies than when communication takes place within the culture [5-7]. All this, of course, requires focusing on the practical orientation of teaching foreign languages, on the educational result, which involves mastering the skills of intercultural communication, possession of intercultural communicative competence.

Intercultural competence is a combination of linguistic knowledge, ways of empathic, and tolerant communication between people of different sociocultural nature and social statuses necessary for intercultural interaction [8-13]. Intercultural communication involves the development of a cultural context, knowledge of a foreign cultural communicative code as a combination of behavioral (language, norms, and rules of behavior) and psycho-mental (mentality, mental characteristics) codes.

\subsection{Bilingualism and bilingual education}

The development of modern society is associated with increased intercultural communication, which led to the spread of the bilingual learning model $[14,15]$. B. Birner notes that bilingualism or multilingualism is a characteristic phenomenon in many countries: "Multilingualism is not unusual; in fact, this is the norm for most world societies" [16]. If natural bilingualism (due to birth in a family in which parents burn in different languages) is stable and transmitted from generation to generation, then the formation of bilingualism in international communication is a pedagogical task.

In the research literature, there are many definitions of the concept of "bilingualism." So, L. Bloomfield understood bilingualism as the possession of a second language at the native level, "native-like control of two languages" [17, p. 55-56], E. Haugen, unlike L. Bloomfield, puts forward minimal requirements for this concept and believes that if a person is able to express the meaning of a sentence in a non-native language, he is a bilingual [18]. The introduction of bilingual principles in teaching methods occurred in the 1960 s. One of the first who introduced the bilingual method as a method of teaching a foreign language was K. Dodson [19]. K. Dodson's bilingual teaching method is based on the introduction of three components into training presentation, practice, production. According to $\mathrm{C}$. Dodson, performance, practice, production is the three main stages of any language lesson.

The principles of C. Dodson's bilingual method are, firstly, the simplification of understanding words and sentences in foreign languages through the use of the native language of students, secondly, the explanation of the meaning of words and sentences of the language should be carried out in practical and non-artificially created situations, and thirdly, a combination of the Direct method (involving live communication) and the grammar-translation method.

If bilingualism is natural and is present in a communicative environment for a child who has grown up in a bilingual environment, then for bilingualism it is typical to learn a second language in the learning process and the occasional use of the academic language in the communication process. Therefore, bilingual teaching technologies are aimed at consolidating the symbolic connections of foreign language units with their equivalents in the native language of the student, while the educational process naturally includes the student in situational relations, updating situational clichés of a foreign language. The situational nature of bilingual education allows us to launch further the mechanism for switching students from one language to another.

The use of bilingual teaching technologies allows the student to master a foreign language in the study of the subject, which plays a significant role not only in the formation of specialist competencies in a particular field but also is of great importance in the further practical expansion of intercultural communication. Thus, the use of bilingual practices in teaching students helps to increase students' motivation in learning a foreign language but also allows for the integration of subject knowledge, which is aimed at understanding the holistic picture of the world.

A feature of bilingual education is that this learning model helps to overcome the isolated perception of a foreign language from other subjects. In the process of learning, a person is "immersed" in a bilingual linguistic space, while linguistic and multicultural factors are interconnected and complement each other. The bilingual environment determines the features of the formation and development of the modern educational environment. The bilingual environment is the organization of language training in various forms, using a variety of didactic materials (audio, video, materials on different media), which are selected by the teacher based on the level of students' language proficiency. It should be noted some problems in the organization of bilingual education. These include problems associated with the preparation of bilingual teachers, providing the learning process with the required teaching materials. 
Bilingual education allows organizing the educational process through a foreign language as a means of learning and communication, the interconnected inclusion of two languages. As a result, the language becomes a learning tool, which introduces features into the learning process, consisting in the fact that when learning the linguistic and substantive components are combined, it actualizes the problem of forming the vocabulary of students.

Essential for this process is the wordsinternationalism, as similar in meaning and terms of expression, words that function in different languages. In this regard, the problem of the interaction of the lexical units of the native language for students with the units of the language they study in the structure of the mental lexicon [20-22].

Practical methods of bilingual education include the introduction of foreign concepts, the explanation of their meanings and their relation to other words, as well as their consolidation through systematic exercises, such as translation, consolidation of speech clichés in the context of situational connections, reproduction of a foreign language text in different temporal and temporal characteristics.

Bilingual education allows students to overcome the language barrier, and increase academic success, improve the communication skills of students in a multinational group. Awareness of the characteristics of cultural and ethnic identity, familiarization with national values is possible due to the communication of different ethnic language groups, which allows students to acquire additional linguistic knowledge, which is a guarantee of successful social mobility. A feature of bilingual education is that it is a foreign language that acts as a means of instruction and intercultural communication. In many countries, interest in learning foreign languages is quite high, there are bilingual education opportunities for any person, regardless of age, effective practices for teaching preschool children and further at all levels of education.

Practice as the appropriate activity of people is considered in our study in the context of bilingual education and intercultural communication. The bilingual practice is a type of sociocultural practice in which the realities of intercultural communications and educational space are integrated. However, in the scientific literature, the question of the essence of bilingual practices has not been sufficiently studied. In our study, bilingual practice is considered as an active activity aimed at the development of the intercultural competence of students as a condition for their successful intercultural communication. The bilingual practice is goal-oriented, implemented in a variety of forms, including in the form of an individual student self-design. Bilingual practice presupposes inclusion in various communicative acts and types of activities (design, creative, volunteer) that enable self-expression and self-development.

\section{Conclusion}

The conducted study expanded the knowledge of bilingual practices, their role in intercultural communication, which acquires a special significance in the context of globalization. The study showed that in modern conditions the role of bilingual practices is increasing, ensuring the development of intercultural competence, the acquisition of intercultural communication experience in the context of updating the socio-cultural situation in the world. In the era of globalization, socio-cultural development proceeds by strengthening the interconnectedness and interdependence of different cultures, expanding contacts between social groups and individuals belonging to different cultures, and enriching cultures.

The development of intercultural competence as an ability to understand and perceive the identity of another culture, and to build a dialogue of cultures is becoming increasingly important.

Bilingual practices make it possible to establish new socio-cultural ties, study a different culture and language, achieve mutual understanding of cultures, design new information channels, include university students in various types of bilingual activities in the context of modern vectors of intercultural communications.

It should be concluded that the inclusion of students in diverse bilingual practices provides not only educational and communication effects, but also requires bilingual training of teachers, their understanding of the diversity of bilingual practices, the design and implementation of new types of bilingual practices, for example, project and distance learning, and the search for new educational bilingual learning technologies.

\section{References}

1. G. Trager, E. Hall, Culture as Communication: $A$ Model and Analysis. (New York 1954).

2. D. J. Goodman, G. Ritzer, Sociological Theory. (Sixth Edition. McGraw Hill 2004).

3. J. N. Pieterse, Globalization and culture: Three paradigms, Globalization and Culture: Global Mélange. J. N. Pieters (Ed.). Lanham, 41-58 (Maryland: Rowman \& Littlefield Publishing Group, Inc., 2003).

4. R. Robertson, Globalization: Social Theory and Global Culture. (London, SAGE 1992).

5. M. Y. Gudova, M. O. Guzikova, Analyzing the Intercultural and Multilingual University Space: Methodological Foundations, Facets of culture in the age of social transition proceedings of the all-Russian research conference. Borisovna, 188-192 (K.N. (Ed.). KNOWLEDGE E, 2018).

6. M. Gudova, I. Lisovetc, Synesthetic artistic perception in the era of post literacy, ADVED 2017: 3rd international conference on advances in education and social science. 958-961 (Uslu, F. Ed. International Organization Center of Academic Research, 2017). 
7. E. Cherepanova, M. Soboleva, Philosophy in contemporary Russia - SOS: problems of modern development of university theory and practice, Zbornik matice srpske za slavistiku-Matica srpska journal of Slavic studies, 94, 159-172 (2018).

8. V. Voronin, M. Itskovich, The model of text comprehension within cognitive values and semantics, ICERI2017: 10th international conference of education, research and innovation, 4333-4338 (2017).

9. I. Gudova, Scientific imperialism in the global educational space, Proceedings of INTCESS 20196th international conference on education and social sciences, 155-156 (Uslu, F. (ed.). International Organization Center of Academic Research 2019).

10. A. Gadomski, T. Itskovich, O. Mikhailova, The language of Russian Orthodoxy in lexicographical lighting, Quaestio Rossica, 6(4), 1246-1255 (2018).

11.E. G. Trubina, Authorities' priorities and citizens' experience through the lens of multiscalarity: The case of Kuldiga (Latvia), Siberian Historical Research, 4, 262- 280 (2016).

12. S. Turoma, S. Ratilainen, E. Trubina, At the intersection of globalization and 'civilizational originality': cultural production in Putin's Russia, Cultural Studies, 32(5), 651-675 (2018).

13. E. V. Bakeeva, The ontological sense of the concept of «measure», Rivista di Filosofia Neo-Scolastica, 109 (2), 471-483 (2017).
14. J. Austin, M. Blume, L. Sanchez, Bilingualism in the Spanish-Speaking World, Linguistic and Cognitive Perspectives (Cambridge University Press. UK: Cambridge 2015).

15. M. V. Mosin, L. P. Vodyasova, N. M. Mosina, N. V. Chinaeva, Bilingualism's didactic potential in teaching a foreign language, Integration of Education, 21(4), 751-764 (2017).

16. B. Birner, Bilingualism, Linguistic Society of America. Retrieved from: http://www.linguisticsociety.org/sites/default/files/Bi lingual.pdf

17. L. Bloomfield, Language. (London: George Allen and Unwin, 1933).

18. E. Haugen, The Norwegian Language in America: A Study in Bilingual Behavior. (Philadelphia: University of Pennsylvania Press 1953).

19. C. J. Dodson, Language Teaching and the Bilingual Method (London: Pitman 1967).

20. J. Aitchison, Words in the Mind: An Introduction to the Mental Lexicon. (Malden, MA: Blackwell, 2003).

21. Y.Dong, Sh. Gui, B. Macwhinney, Shared and Separate Meanings in the Bilingual Mental Lexicon, Bilingualism: Language and Cognition, 8(3), 221238 (Cambridge: Cambridge University Press, 2005).

22. A. Pavlenko, The Bilingual Mental Lexicon: Interdisciplinary Approaches (Bilingual Education and Bilingualism). (Great Britain: Cromwell Press Ltd., 2009). 